\title{
Moving towards Virtual Learning Clouds from Traditional Learning: Higher Educational Systems in India
}

\author{
http://dx.doi.org/10.3991/ijet.v9i9.4183 \\ Mrs. Vasanthi Muniasamy, Dr. Intisar Magboul Ejalani, Dr. Anandhavalli \\ King Khalid University, KSA
}

\begin{abstract}
E-Learning has become an increasingly popular learning approach in higher Education institutions due to the rapid growth of Communication and Information Technology (CIT). In recent years, it has been integrated in many university programs and it is one of the new learning trends. But in many Indian Universities did not implement this novel technology in their Educational Systems. ELearning is not intended to replace the traditional classroom setting, but to provide new opportunities and new virtual environment for interaction and communication between the students and teacher. E-Learning through Cloud is now becoming an interesting and very useful revolutionary technology in the field of education. E-Learning system usually requires huge amount of hardware and software resources. Due to the cost, many universities in India do not want to implement the E-Learning technology in their Educational system and they cannot afford such investments. Cloud Virtual Learning is the only solution for this problem. This paper presents the benefits of using cloud technology in E-Learning system, working mode, Services, Models. And also we discuss the cloud computing educational environment and how higher education may take advantage of clouds not only in terms of cost but also in terms of Security, flexibility, portability, efficiency and reliability. And also we present some educational clouds introduced by popular cloud providers.
\end{abstract}

Index Terms-E-Learning, Cloud Computing, Service Models, Deployment Models, Cloud Service Providers

\section{INTRODUCTION}

Education is an important in everyone life. No one can survey without education in this fast growing world. Having an educated population is very important when it comes to the overall well being of a nation. Every government invests more money for their citizen's education. Now- a - days Communication and Information Technology has inevitably become the most powerful tool. Technology is regarded as a major revolution and this has a significant impact on education. The use of communication and Information Technology (CIT) and the Internet are the new paradigm of learning in 21 st century. These technological advancements allow people to easily access, gather, analyze, and transfer data \& knowledge. Learning communities have evolved from the traditional classroom to online distance education settings in which students come together in a virtual environment to exchange ideas, solve problems, explore alternatives, and create new meanings along a connected journey. Former president of India, Dr. A.P.J. Abdul Kalam exhorted the nation to create a World Knowledge Platform through convergence of all technologies, methodologies and core competences of all for development, production and marketing of knowledge products. He is of the considered view that technology can add value to Knowledge Management $(\mathrm{KM})$, help create vital resources and remove isolation of people by connecting them to expert human resources. ELearning exploits interactive technologies and communication systems to improve the learning experience. A click of a mouse button provides any student anywhere with unprecedented opportunities to learn. It has the potential to transform the way we teach and learn across the board. It can raise standards, and widen participation in lifelong learning. It cannot replace teachers and lecturers, but alongside existing methods it can enhance the quality and reach of their teaching, and reduce the time spent on administration. It can enable every learner to achieve his or her potential, and help to build an educational workforce empowered to change. It makes possible a truly ambitious education system for a future learning society. In the 'Information Age' where the need for 'knowledge workers' increases as the need for manual workers decreases, 'lifelong learning' is seen as key to the continued success of modern society. 'E-Learning' is considered by many as the only viable solution to the problem of delivering the resources required facilitating lifelong learning. Some of the benefits of E-Learning are cost effective and saves time, Learning 24/7, anywhere, makes tracking of course progress a breeze, discreet. Use of e-learning in higher education has the following advantages: lower costs, time saving, flexibility, faster response, greater effectiveness, better morale, greater competitiveness and easy access to information and resources. Poor or insufficient technology infrastructure can cause more damage. The most important of these include the costs of infrastructure support and its maintenance and the proper training of teachers and students to enable them to make the most of the technology to success. Cloud computing is a new paradigm where we don't have to spend more money to build and maintain the IT infrastructure. When we need to use computing resources like application software, we just borrow that facility from the cloud providers and access those services via the Internet. In return we pay the service provider as we use the computing power. In short form, we didn't need to buy any hardware and software to implement the virtual learning thus it helps us to minimize the investment of hardware and CIT maintenance teams. In this paper, we study how cloud computing can benefit elearning education in India. We discuss the cloud computing educational environment and how higher education 
may take advantage of clouds not only in terms of cost but also in terms of Security, flexibility, portability, efficiency and reliability. And also we present some educational clouds introduced by popular cloud providers.

\section{CURRENT EDUCATIONAL SYSTEM IN INDIA}

For many decades India's educational system has produced some of the top minds in the world which have eventually seemed to migrate to other parts of the world. Today we might see such people in the communities serving as doctors, engineers or even as professors at university. One might question, how is a country that faces so many hardships able to create great minds? Is it due to a superb educational system or is it because India has such a large population to draw from? Some individuals might argue that it is a combination of the two. Although India educates many PhD's students who may settle to work in different parts of the world, it can however be suggested that its educational system is still suffering. Many people across the world are aware that India has educated people with a lot of desirable skills. Large corporations from around the world have setup divisions to take advantage of the large educated labor pool. Having a large educated population might naturally and very well so be a sign of a strong educational system. In the case of India though, for many poor people a strong educational system is by no means true. Current education in India is not keeping up with demand and for some individuals it is not providing results. Few people are choosing teaching as a profession, and this has resulted in a shortage of good teachers. Often inexperienced teachers are employed and as a result the quality of education drops. Although computers have been around for awhile they are still not accessible for many people in the world. This is due to the high cost of infrastructure. The reasons why the number of computer use is so low could be attributed to the high cost of computer hardware and maintenance. Learning through Cloud computing technology is the best solution for the educational problem.

\section{Cloud COMPUTING}

Cloud computing is a model for enabling ubiquitous, convenient, on-demand network access to a shared pool of configurable computing resources (e.g., networks, servers, storage, applications, and services) that can be rapidly provisioned and released with minimal management effort or service provider interaction. This cloud model is composed of five essential characteristics, three service models, and four deployment models.

\section{A. Essential Characteristics:}

On-demand self-service: A consumer can unilaterally provision computing capabilities, such as server time and network storage, as needed automatically without requiring human interaction with each service provider.

Broad network access: Capabilities are available over the network and accessed through standard mechanisms that promote use by heterogeneous thin or thick client platforms (e.g., mobile phones, tablets, laptops, and workstations).

Resource pooling: The provider's computing resources are pooled to serve multiple consumers using a multitenant model, with different physical and virtual resources dynamically assigned and reassigned according to consumer demand. There is a sense of location independence in that the customer generally has no control or knowledge over the exact location of the provided resources but may be able to specify location at a higher level of abstraction (e.g., country, state, or datacenter). Examples of resources include storage, processing, memory, and network bandwidth.

Rapid elasticity: Capabilities can be elastically provisioned and released, in some cases automatically, to scale rapidly outward and inward commensurate with demand. To the consumer, the capabilities available for provisioning often appear to be unlimited and can be appropriated in any quantity at any time.

Measured service: Cloud systems automatically control and optimize resource use by leveraging a metering capability (Typically this is done on a pay-per-use or charge-per-use basis) at some level of abstraction appropriate to the type of service (e.g., storage, processing, bandwidth, and active user accounts). Resource usage can be monitored, controlled, and reported, providing transparency for both the provider and consumer of the utilized service.

\section{B. Service Models}

Software as a Service (SaaS): The capability provided to the consumer is to use the provider's applications running on a cloud infrastructure. The applications are accessible from various client devices through either a thin client interface, such as a web browser (e.g., web-based email), or a program interface. The consumer does not manage or control the underlying cloud infrastructure including network, servers, operating systems, storage, or even individual application capabilities, with the possible exception of limited user-specific application configuration settings. Shown in Figure 1

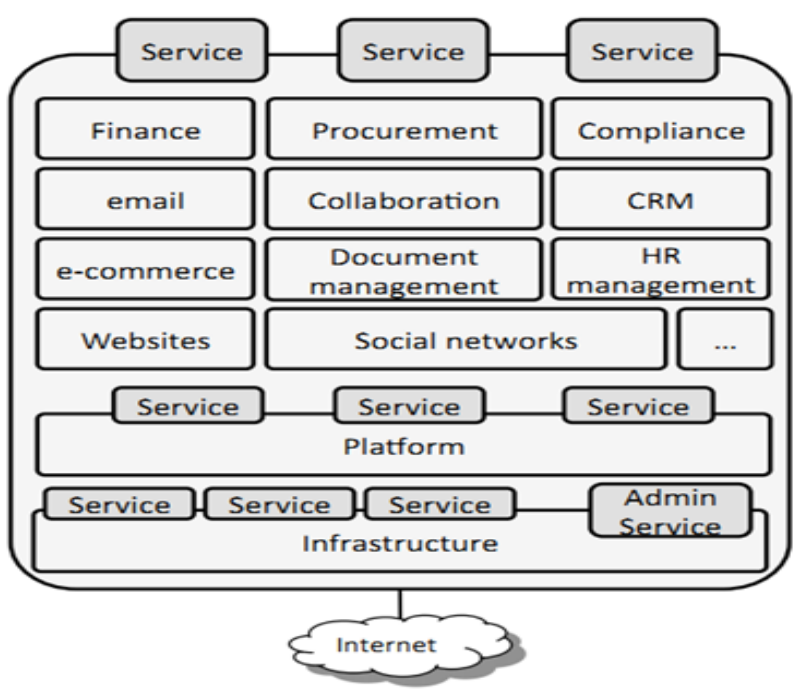

Figure 1. Software-as-a-Service (SaaS) Stack

Platform as a Service (PaaS): The capability provided to the consumer is to deploy onto the cloud infrastructure consumer-created or acquired applications created using programming languages, libraries, services, and tools supported by the provider. The consumer does not manage or control the underlying cloud infrastructure including network, servers, operating systems, or storage, but has control over the deployed applications and possibly configuration settings for the application-hosting environment. 


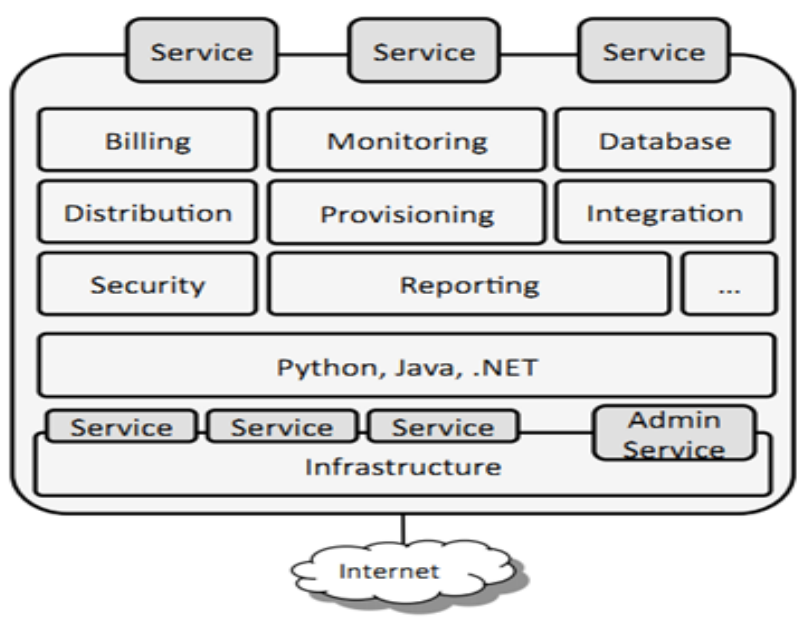

Figure 2. Platform-as-a-Service (PaaS) Stack

Infrastructure as a Service (IaaS): The capability provided to the consumer is to provision processing, storage, networks, and other fundamental computing resources where the consumer is able to deploy and run arbitrary software, which can include operating systems and applications. The consumer does not manage or control the underlying cloud infrastructure but has control over operating systems, storage, and deployed applications; and possibly limited control of select networking components (e.g., host firewalls).

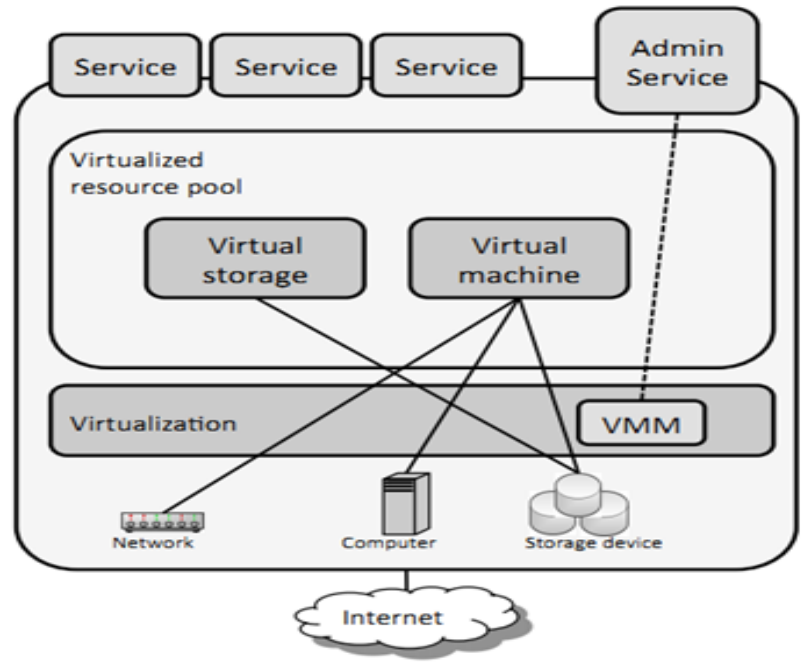

Figure 3. Infrastructure-as-a-Service (IaaS) Stack

\section{Deployment Models}

The cloud can be used by public (public Cloud) and a single organization (Private Cloud) or more than one organization that share the same interests and policies (Community Cloud) and mixture of public and private cloud (Hybrid Cloud). These are explaining below in detail.

Private cloud: The cloud infrastructure is provisioned for exclusive use by a single organization comprising multiple consumers (e.g., business units). It may be owned, managed, and operated by the organization, a third party, or some combination of them, and it may exist on or off premises. Shown in Figure 4

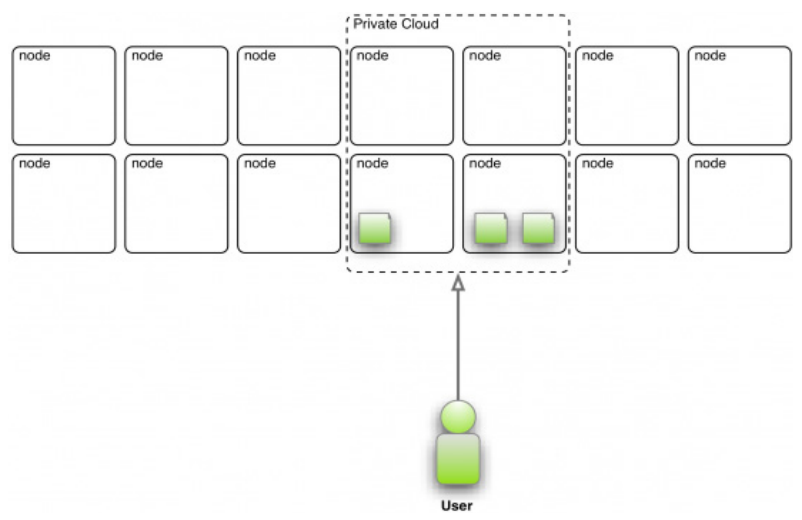

Figure 4. A user accessing a private cloud

Public cloud: The cloud infrastructure is provisioned for open use by the general public. It may be owned, managed, and operated by a business, academic, or government organization, or some combination of them. It exists on the premises of the cloud provider. Shown in Figure 5

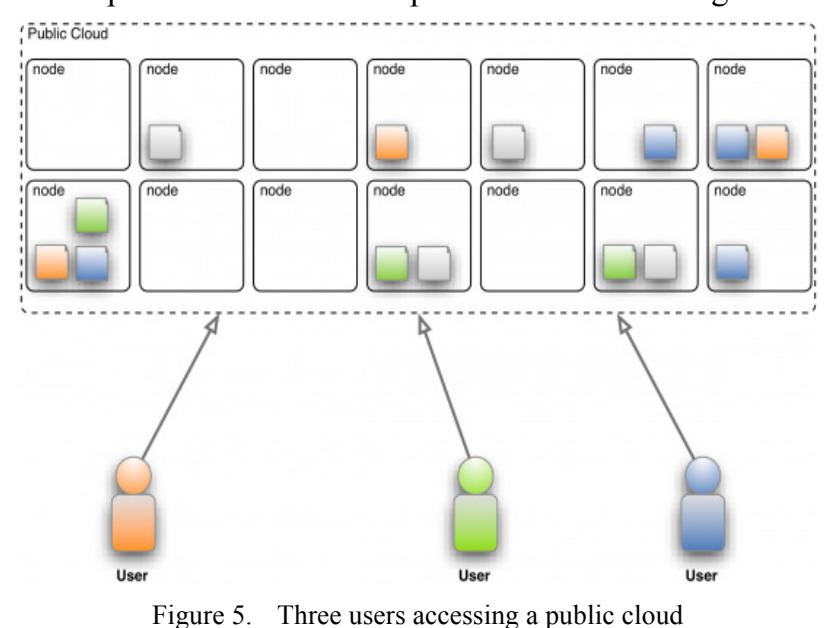

Community cloud: The cloud infrastructure is provisioned for exclusive use by a specific community of consumers from organizations that have shared concerns (e.g., mission, security requirements, policy, and compliance considerations). It may be owned, managed, and operated by one or more of the organizations in the community, a third party, or some combination of them, and it may exist on or off premises. Shown in Figure 6

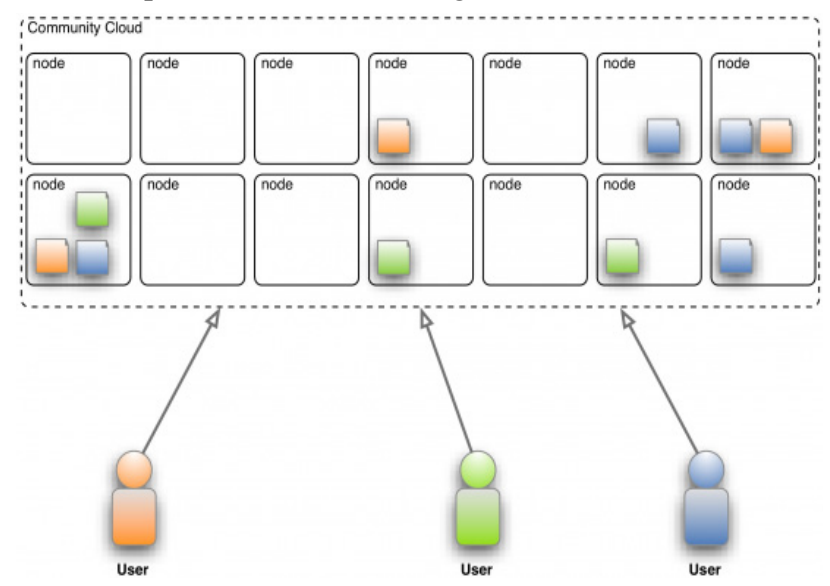

Figure 6. Three users accessing a community cloud 
Hybrid cloud: The cloud infrastructure is a composition of two or more distinct cloud infrastructures (private, community, or public) that remain unique entities, but are bound together by standardized or proprietary technology that enables data and application portability (e.g., cloud bursting for load balancing between clouds. Shown in Figure 7

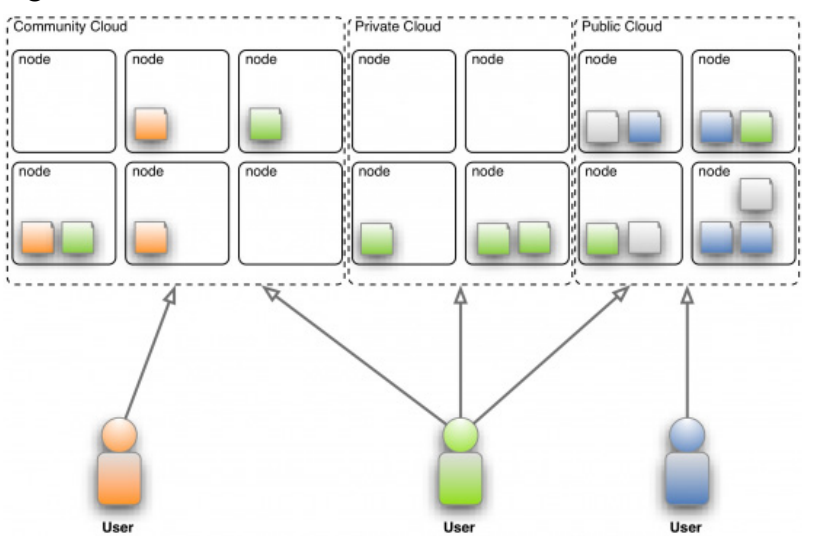

Figure 7. Hybrid cloud usage

\section{Cloud Computing for Colleges and Universities}

Public cloud computing will deliver benefits beyond the major universities. Its advantages may be even more pronounced in small colleges that have not yet achieved high levels of computerization, or do not have and have trouble recruiting people with adequate IT skills, or those worried about their ability to secure and protect data. By contracting with a cloud service provider (perhaps another, larger university), that small college can adopt state-of-the-art applications and services, enabling the college to skip a whole generation of academic computing, thereby bypassing many of the costly and debilitating challenges discussed previously. Figure 8 shows some popular Cloud Service Providers.

\section{Cloud BASED E-LEARNING}

With the increase in number of students, rapid growth of Education content and changing IT infrastructure, the educational institutes are confronted with a dramatic increase in costs and a decrease in budgets which leads to the need of finding some alternative for their e-learning solutions. Also, the current e-learning systems are not scalable and do not lead to the efficient utilization of the resources. As a response to this increase in pressure and to increase the efficiency and availability of their current elearning system, the educational institutes may adopt a service oriented approach. The potential efficiency of using cloud computing in higher education has been recognized by many universities such as University of California, Washington State University, School of Electrical Engineering and Computer Science, higher education institutes from UK, Africa, US and KSA.

In cloud based e-learning systems, the institutions are responsible for content creation, management and delivery while the cloud service provider is responsible for system construction, development, management and maintenance. The institutes are charged according to the usage that directly depends on the number of students.

In [2], Thongchai Kaewkiriya and Nattavee Utakrit have proposed a model for e-learning using cloud computing which is shown in fig.9.
In this model, the request from the user is sent to the cloudService provider which in turn connects to the elearning Cloud in order to give response to the user's query

\section{A. Benefits of Cloud based E-Learning}

The potential benefits of cloud based e-learning include:

Mobile, decentralized and just in time learning: A more flexible learning mechanism is provided that aligns itself more closely to the learner's day to day activities. In taking content outside the learning structures, cloud computing allows for the delivery of learning anytime and anywhere.

Cost effective: According to Marc Benioff, CEO of Salesforce.com, "the cloud services companies of all sizes the cloud is for everyone. The cloud is a democracy". If used properly, it is highly cost effective as institutes have to pay only for the server space they use and costs of maintenance and updates.

Speed of implementation and updating: Implementation can be done in a short span of time. Due to this, the needs of the learner can be given more attention as compared to IT implementation and maintenance of infrastructure.

Virtualization: Replacement of a server can be done very easily and rapidly as a clone can be created due to virtualization, thereby reducing the cloud downtime.

Easy to monitor data access: Monitoring is an easy task as only one place has to be supervised, not thousand systems belonging to an institution.

More personalized learning experience: The open and collaborative nature of the cloud opens up opportunity for more contributions from other people within the learning environment.

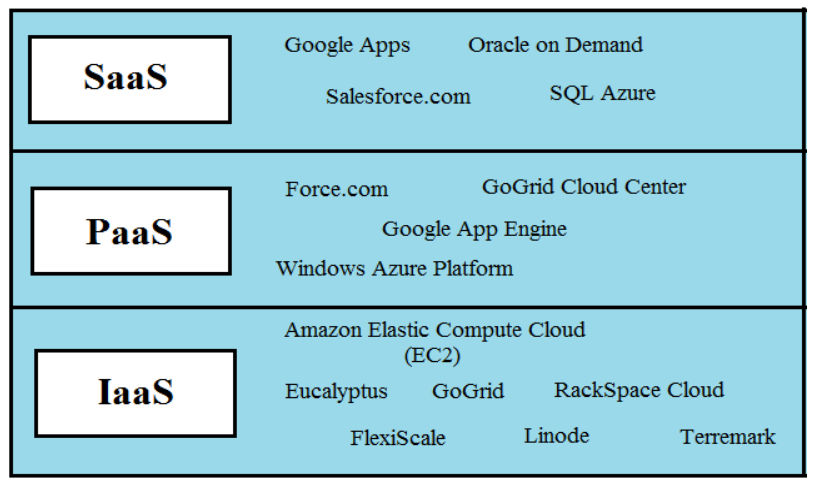

Figure 8. Cloud Service Providers

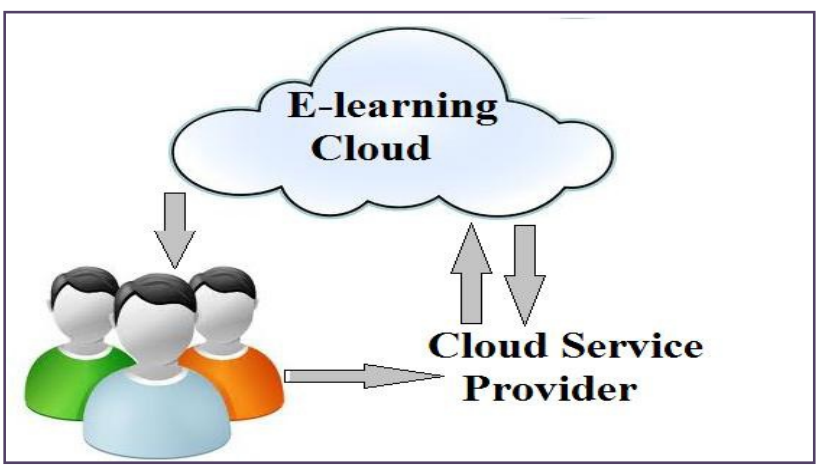

Figure 9. Abstract model of Cloud Computing based E-learning 
Least dependency on IT department: Traditionally, IT worked hand in hand with the learning organization. Due to this, priority was given to the creation of platforms and their maintenance. The cloud has a potential to change this scenario. The priority will be given to the learning content which is more beneficial for the learner. In conclusion educational cloud computing environment offers a wide range of services in platform, application and infrastructure levels to learners, teachers, researchers and academic staff members.

\section{ClOUd ARCHITECTURE FOR E-LEARNING}

The architecture of a system that uses cloud computing as an e-learning solution is shown in Figure 10.

- Infrastructure Layer is composed of dynamic and scalable resources such as physical memory, CPU and memory etc.

- Software Resource Layer mainly consists of operating system and middleware to provide interface to the software developers for easy development of applications that will be made available to the end users.

- Resource Management layer is used to achieve loose coupling of hardware and software resources so as to provide on demand service.

- Service Layer has three levels namely IaaS, PaaS and SaaS that help the cloud users to use various cloud services.

- Application Layer includes specific applications to integrate teaching resources with cloud computing model.

\section{Cloud Service PROVIDERS - INDIA \& GLOBAL MARKET}

We listed out some famous cloud service providers (India and Global) below.

\section{Zenith InfoTech}

- Base Location: Mumbai, India

- Cloud Offering: PROUD

- Cloud Type: IaaS

IT product development and Innovation Company With an investment of INR 175-crore, this is considered as India's one of the most ambitious R\&D efforts in IT.

\section{Wolf Frameworks}

- Base Location: Bangalore, India

- Cloud Offering: Wolf PaaS

- Cloud Type: PaaS

Founded in 2006, it provides affordable cloud service with $99.97 \%$ Service Level Assurance. Wolf is a browser based On Demand Platform-as-a-Service (PaaS) for rapidly designing and delivering database driven multi-tenant Software-as-a-Service (SaaS) applications.. Coding only comes in when you need custom templates or specific integration Business Rule actions

\section{OrangeScape}

- Base Location: Chennai, India

- Cloud Offering: OrangeScape Cloud

- Cloud Type: PaaS

The experience of building business applications of varying complexity across industries has made OrangeScape the most comprehensive PaaS (Platform as a Service)

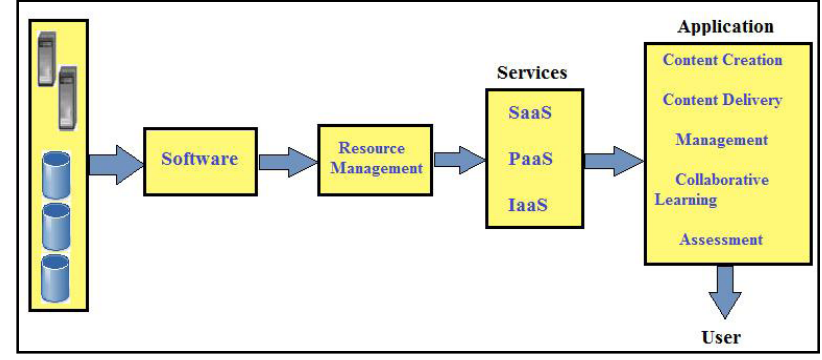

Figure 10. Cloud Computing based E-Learning Architecture

offering in the market. You can transform your idea into a SaaS application and can showcase them to your investors, partners and potential customers. It has an impressive list of customers' viz. Ford, Pfizer, Geojit, Sify etc.

TCS

- Base Location: India

- Cloud Offering: ITaaS

- Cloud Type: IaaS +SaaS

ITaaS is a Nano in software. ITaaS framework is a onestop shop for total end-to-end IT and hardware solutions. It includes hardware, network, bandwidth \& business software. Currently ITaaS is available for 5 sectors: Manufacturing, Retail, Healthcare, Education and Professional Services.

\section{Cynapse India}

- Base Location: Mumbai, India

- Cloud Offering: Cyn.in

- Cloud Type: IaaS + on Demand SaaS

Cyn.in on demand is a cloud hosted service and is the quickest way to get your own Cyn.in server, without the hassles of having to set it up. With a Cyn.in on-demand system, you get a dedicated virtual server running a Cyn.in appliance that is maintained \& updated by Cynapse and hosted by Amazon, ensuring an infrastructure-free and worry-free Cyn.in experience.

\section{Wipro Technologies}

- Base Location: India

- Cloud Offering: Wipro w-SaaS

- Cloud Type: SaaS

Wipro has built w-SaaS, a platform for rapid SaaS enablement and deployment on cloud, using some of the commonly accepted trends in software engineering and open standards. Wipro chose Oracle (Oracle Database, Oracle WebLogic Application Server and Oracle VM) as the deployment platform for w-SaaS enabled applications. The software vendor can deploy the same application onpremise or on the cloud using w-SaaS and Oracle.

\section{Netmagic Solutions}

- Base Location: Mumbai, India

- Cloud Offering:

\section{- CloudNet \\ - CloudServe \\ - PrivateCloud}

- Cloud Type: IaaS

Netmagic looks like a dedicated cloud provider in Indian market with a potential to become a big player in near future.

Reliance Data Center (a division of Reliance Communications)

- $\quad$ Base Location: India 
- Cloud Offering: Reliance Cloud Computing Services

- $\quad$ Cloud Type: IaaS + SaaS + PaaS

A hosted infrastructure service based on the Microsoft platform for Enterprises and SMBs - geared to deliver India's largest cloud infrastructure.

\section{Infosys Technologies}

- Base Location: Bangalore, India.

- Cloud Offering: Cloud based Solution for Auto Sector.

- Cloud Type: SaaS

Infosys' Cloud Computing Consulting and Service offerings enable organizations to adopt the Cloud Computing platform selectively and effectively. But brand Infosys, the most recognized IT brand from India has to put significant efforts to catch up with other cloud providers.

\section{Synage}

- Base Location: Mumbai, India.

- Cloud Offering: DeskAway

- Cloud Type: SaaS

Web company delivering software as a service (SaaS) over the nternet to the global audience. DeskAway is the flagship product of Synage, based on a monthly or yearly subscription model, requiring zeroinstallation, and powered by a cutting-edge user interface, It is the future of project \& team collaboration software. Currently, most of them are start-ups and are nowhere near the top global cloud vendors like Amazon, Google, Salesforce or Microsoft [listed below] but they have the potentials to compete with these giants in near future.

Amazon: Specializes in IaaS. It offers through Amazon Web Services (AWS): Amazon Elastic Compute Cloud (EC2), Amazon SimpleDB, Amazon CloudFront, Amazon SQS. It claims to have 82 billion objects stored in Amazon S3 (Simple Storage Service). The Amazon EC2 (Elastic Compute Cloud) lets the users configure and control computing resources while running them on Amazon's environment

Google: The Google's App Engine lets the users build, run and maintains their applications on Google's infrastructure. It Specializes in PaaS \& SaaS. As SaaS it offers Google Apps: a web-based communication, collaboration \& security apps which include, Gmail, Google Calendar, Google Talk, Google Docs \& Google Sites. 15 Sep 2009, Google announced that it will provide GovCloud, which will host Google Apps in a separate data environment with enhanced encryption for meeting state and government security standards.

As PaaS it offers Google App Engine: a platform for developing and hosting web applications in Googlemanaged data centers. Currently, the supported programming languages are Python and Java (by extension other JVM languages are also supported).

You build your application using Google's PaaS and Google handles deploying code to a cluster, monitoring, failover, and launching application instances as necessary. Good news, Google App Engine is free, but only up to a certain level of used resources.

VMware: It offers vCloud: Run, secure and manage applications in the private cloud or have them federated on-demand to partner-hosted public clouds. vCloud is giving a tough competition to more established Amazon's AWS.

It was recently in the news for partnership with Cisco \& EMC, to offer equipment called Vblocks and support a new joint venture called Acadia that will help business customers and service providers build out clouds based on the Vblock gear packages.

RackSpace The RackSpace provides servers-ondemand via a cloud-driven platform of virtualized servers. The company specializes in IaaS. It offers Rackspace Cloud, cloud services are: Cloud Sites, Cloud Servers, Cloud Files.

Salesforce.com This is a Force.com development platform. This provides a simple user interface and lets users $\log$ in, build an app and push it in the cloud. Leader in SaaS. It offers Salesforce CRM (Sales Cloud 2, Service Cloud 2) \&Force.com Platform (Custom Cloud 2, Development Platform).

Microsoft The Microsoft's Windows Azure is a cloud computing platform offering an environment to create cloud apps and services. It specializes in PaaS. It offers Azure, a Windows-as-a-service platform consisting of the operating system and developer services that can be used to build and enhance Web-hosted applications. Azure is available for VS 2008via Web Platform Installer.

Appistry The Appistry'sCloudQ platform is efficient in delivering a runtime application platform. This platform is very useful to create scalable and service oriented applications.

AppScale The AppScale is an open source platform for Google App Engine applications.

AT\&T The AT\&T allows access to virtual servers and manages the virtualization infrastructure. This virtualization infrastructure includes network, server and storage.

Engine Yard The Engine Yard is a Rails Application cloud computing platform.

Enomaly Enomaly provides the Infrastructure-as-aService platform.

FlexiScale The FlexiScale offers a cloud computing platform that allows flexible, scalable and automated cloud infrastructure.

GCloud3 The GCloud3 offers private cloud solution in its gPlatform.

Gizmox The Gizmox Visual WebGUI platform is best suited for developing new web apps and modernizes the legacy apps based on ASP.net, DHTML, etc.

GoGrid The GoGrid platform allows the users to deploy web and database cloud services.

LongJump The LongJump offers a Business Application Platform, a platform-as-a-Service (PaaS).

\section{Benfeits of Cloud BASED E-LEARNing}

There are numerous advantages when the e-learning is implemented with the cloud computing technology, they are:

A. Low cost: E-Learning users need not have high end configured computers to run the e-learning applications. They can run the applications from cloud through their PC, mobile phones, tablet PC having minimum configuration with internet connectivity. Since the data is created and accessed in the cloud, the user need not spend more money for large memory for data storage in local ma- 
chines. Organizations also need to pay per use, so it's cheaper and need to pay only for the space they need.

B. Improved performance: Since the cloud based elearning applications have most of the applications and processes in cloud, client machines do not create problems on performance when they are working.

C. Instant software updates: Since the cloud based application for e-learning runs with the cloud power, the software's are automatically updated in cloud source. So, always e-learners get updates instantly.

D. Improved document format compatibility: Since some file formats and fonts do not open properly in some $\mathrm{PCs} /$ mobile phones, the cloud powered e-learning applications do not have to worry about those kinds of problems. As the cloud based e-learning applications open the file from cloud.

E. Benefits for students: Students get more advantages through cloud based e-learning. They can take online courses, attend the online exams, get feedback about the courses from instructors, and send their projects and assignments through online to their teachers.

F. Benefits for teachers: Teachers also get numerous benefits over cloud based e-learning. Teachers are able to prepare online tests for students, deal and create better content resources for students through content management, assess the tests, homework, projects taken by students, send the feedback and communicate with students through online forums.

G. Data security: A very big concern is related to the data security because both the software and the data are located on remote servers that can crash or disappear without any additional warnings. Even if it seems not very reasonable, the cloud computing provides some major security benefits for individuals and companies that are using/developing e-learning solutions.

\section{CONCLUSION AND FUTURE WORK}

India has many obstacles to overcome before it can offer its entire population access to an advance technology like e-learning. Large segments of the population live in poverty and many do not know how to read or write. Also the lack of infrastructure around the country only allows the median to be accessed by upper class who can afford it. But this is no reason for the country to give up on elearning. Although with all the obstacles, the future looks bright for e-learning in India. In India, over the past decade, technology has been seen as an agent of power and control. The government has recognized that embracing technology can make India really powerful by allowing it to urbanize faster to match the clout that western nations already have. In the knowledge economy the main competitive advantage of nations is not their physical assets but the quality and skill of their people. E-learning, if used effectively, can provide education to a large population that would otherwise not have access to it. In India, education through technology is way to irradiate years of caste oppression, poverty and at same time increase literacy. In taking content outside traditional learning structure, cloud computing will essentially allow for the delivery of learning anywhere and at anytime. No longer requiring memory intensive laptops, the cloud will enable learners to access the content from any device like desktop, laptop, PDA, mobile phone etc. as long as they are connected to the network. Cloud based e-learning will enable people to build their learning around their specific needs with the cloud allowing relevant, tailored content to be created for the users without any dependence on IT to update delivery platforms accordingly. This paper presents Moving towards Virtual Learning Clouds from Traditional Learning: Higher Educational Systems in India and shows how universities and institutions can take advantage of the cloud. We believe that cloud computing opens a new era in education and e-learning because it provides a flexible, cost effective and efficient infrastructure that universities and institutions can deploy to allow their faculty, staff and students accomplish their work better and faster than ever. The study presented in this paper helps the leadership and decision makers improve education and provides advises to educational institutions and individuals on the tremendous applications and services available in the cloud. In future we will make a detail study of the famous cloud service providers in the field of Education.

\section{REFERENCES}

[1] Barrie Sosinsky, Cloud Computing Bible, Wiley Publishing, Inc., Indianapolis, Indiana, 2011..

[2] Thongchai Kaewkiriya and Nattavee Utakrit, A Model of an ELearning Management System Based on Cloud Computing and Web Service, Information Technology Journal, Vol.8, No.1, January-June 2012.

[3] A. Fernandez, D. Peralta, F. Herrera and J.M. Benitez, An Overview of E-Learning in Cloud Computing, L. Uden et al. (Eds.): Workshop on LTEC 2012, AISC 173, pp. 35-46. Springer-Verlag Berlin Heidelberg

[4] Cloud Computing Articles. Cloud Computing Education http://www.code2cloud.com/cloudcomputing-education/

[5] E-Learning using Cloud Computing, Utpal Jyoti Bora, Majidul Ahmed.

[6] Wikipedia, http://en.wikipedia.org/wiki/Virtualization

[7] https://www.cisco.com/web/offer/email/43468/5/Cloud_Computin g_in_Higher_Education.pdf

[8] Wikipedia, http://en.wikipedia.org/wiki/cloud computing

[9] Cloud Computing Articles, SaaS + PaaS + IaaS. Free Cloud Apps for Educational Institutes: Schools, Colleges, Universities. http://www.techno-pulse.com/2010/08/free-cloud-appseducational-institutes.html

[10] A New Trend For E-Learning In KSA Using Educational Clouds" Abdullah Alshwaier, Ahmed Youssef and Ahmed Emam

[11] http://www.techno-pulse.com/2009/12/top-cloud-computingservice-providers.html

\section{AUTHORS}

Mrs. Vasanthi Muniasamy is Lecturer, Department of Information Systems, King Khalid University, KSA, wmsami@kku.edu.sa.

Dr. Intisar Magboul Ejalani is Asst. Professor, Department of Management, King Khalid University, KSA, ealjelani@kku.edu.sa.

Dr. Anandhavalli is Associate Professor, Department of Information Systems, King Khalid University, KSA, anandhigautham@gmail.com.

Submitted 29 September 2014. Published as resubmitted by the authors 30 October 2014. 